\title{
Warfarin-related skin necrosis
}

\author{
Tristan MB de Chalain MSc MD FCSSA FRCSC, Glyn E Jones MD FCSSA \\ The Emory Clinic and Crawford W Long Hospitals, Atlanta, Georgia
}

\begin{abstract}
TMB De Chalain, GE Jones. Warfarin-related skin necrosis. Can J Plast Surg 1996;4(4):209-212. Skin and soft tissue necrosis may be an unexpected and unpredictable consequence of warfarin therapy, occurring in $0.01 \%$ to $0.1 \%$ of patients receiving the drug. Classically, the archetypal patient is female, middle-aged or older, and the area of necrosis occurs in areas of abundant fat, such as breast, thigh or abdomen. The onset begins three to 10 days after commencing therapy. Two cases of warfarin-related skin necrosis are presented. One is a classical abdominal presentation. The other is a much rarer presentation of warfarin necrosis affecting the hand. The implications of the variable presentations in terms of pathophysiology and treatment strategies are discussed.
\end{abstract}

Key Words: Coumadin, Necrosis, Skin, Soft tissue, Warfarin

\section{Nécrose cutanée associée à la warfarine}

RÉSUMÉ : La nécrose de la peau et des tissus mous peut être une conséquence inexpliquée et imprévisible du traitement par la warfarine qui affecte de $0,01 \%$ à $0,1 \%$ des patients recevant ce médicament. En général, il s'agit d'un patient de sexe féminin, d'âge moyen ou plus âgé, et la nécrose affecte les zones où les tissus adipeux sont abondants comme les seins, les cuisses ou l'abdomen. Le phénomène se déclenche de trois à dix jours après le début du traitement. Deux cas de nécrose cutanée associée à la warfarine sont présentés ici. L'un est une présentation abdominale classique, l'autre est une présentation beaucoup plus rare de nécrose associée à la warfarine, affectant la main. Les répercussions de ces présentations variables en terme de physiopathologie et de stratégie thérapeutique sont également abordées ici.

Warfarin sodium, one of the more potent congeners of 3,3'-methylene-bis-4hydroxycoumarin or dicumarol, is marketed under the brand name Coumadin (Du Pont Pharma), and is the most commonly prescribed oral anticoagulant in North America (1). During the 1920s a hitherto unrecognized hemorrhagic disorder of cattle, associated with the chronic ingestion of spoiled sweet clover hay, was reported. However, it was not until 1941 that Link et al (2) were able to isolate dicumarol as the causative agent. During the same year, research at the Mayo clinic showed that dicumarol prolonged the prothrombin time in human subjects, apparently without adverse side effects (3).

In 1943, Flood et al (4) reported the first case of warfarin-related skin necrosis, but it was not until Verhagen's 1954 (3) report that the association between skin necrosis and warfarin anticoagulation was made. Since that time, there have been more than 300 reports of this poorly understood, but fortunately rare complication of oral anticoagulant therapy (5). 
The complication of skin and soft tissue necrosis is one of the more unusual complications of warfarin therapy (6). It is more prevalent in women, the female:male ratio being 3:1 (5). The areas most commonly involved are the breasts, abdomen, thighs and buttocks, although necrosis of unusual areas, such as the penis (7) and dorsum of the foot and ankle $(8,9)$, have been reported. While the cause is believed to be a defect in the clotting mechanism, the exact mechanism remains unclear.

This report presents two new cases of warfarin-related skin and soft tissue necrosis and reviews current understanding of the pathophysiology of the condition. The limited treatment options available to the clinician are also discussed, in the light of what is believed to be the first clinical presentation of warfarin-related skin necrosis involving a hand or upper extremity below the elbow.

\section{CASE PRESENTATIONS}

\section{Case 1}

A 53-year-old Caucasian female presented to her internist with a putative 'cellulitis' of the dorsum of her left hand. Approximately two months previously, she had been an in-patient in hospital, receiving total parenteral nutrition via a central line. This was complicated by thrombosis of the left subclavian and left internal jugular veins, for which she received intravenous heparin and then oral warfarin for systemic anticoagulation. She was discharged fom hospital at the end of December 1994, and presented again on January 21, 1995, approximately one month after commencing her oral warfarin. On examination, she was thought to have a cellulitis of the hand, with fevers of $38.5^{\circ} \mathrm{C}$ and marked pain and tenderness. There was no palpable lymphadenopathy, however, and although there was some left shift of the differential leukocyte count, with $82 \%$ polymorphonuclear forms, the total white cell count was only $7.9 \times 10^{9} / \mathrm{L}$. The hand itself showed exquisite tenderness and was markedly painful. The lesion consisted of an area, roughly $2 \times 2.5 \mathrm{~cm}$ over the central dorsum of the left hand; there was a large bullous lesion with a zone of central necrosis, an ecchymotic border and a peripheral zone of violaceous erythema. Deeper structures, such as the superficial fascia and tendons, did not appear to be involved, although hand movements were limited by pain. She was treated with intravenous ceftriaxone, pending culture results, with little improvement. Repeated attempts at culture of infecting organisms failed to reveal a microbial pathogen. Surgical debridement showed only necrosis of the skin and subcutaneous fat with complete sparing of the fascia overlying the extensor tendons.

As the investigation and work up continued, the diagnosis of a warfarin-related necrosis was considered, despite the unusual features such as 'delayed' time of onset and bizarre anatomical location. Accordingly, protein $\mathrm{C}$ and $\mathrm{S}$ levels were checked, and the patient had slightly reduced levels of protein $\mathrm{S}$ (50 U versus normal range of $60 \mathrm{U}$ to 140 $\mathrm{U})$, although protein $\mathrm{C}$ was normal. The initial histological reports showed nonspecific changes of ulceration and acute and chronic inflammation. A definitive diagnosis could not be reached, and the differential included pyoderma gangrenosum and leucocytoblastic vasculitis. Treatment of the hand, after an initial surgical debridement, was expectant, with rest, elevation and serial dressing changes. Her warfarin therapy was stopped. On this regimen she made steady progress and was discharged three weeks after admission. Her hand has continued to heal well and retains good function. 
Pathological finding: The gross specimen was a $1 \times 0.3 \times 0.3 \mathrm{~cm}$ firm brown fibrous tissue submitted in formalin. Microscopic findings were collagenous tissue consistent with dermis. At one sectional edge, basophilic fibrinopurulent material with extravasated erythrocytes and a mixed inflammatory cell infiltrate were present. This area was consistent with an ulcer bed. Mixed inflammatory cell infiltrates were present primarily in a perivascular distribution. Near the section of the edge where the fibrinopurulent material was located, there was a longitudinally sectioned small blood vessel containing brightly eosinophilic amorphous fibrinoid material in the vessel wall. Neutrophils were present in the vessel lumen, yet the endothelial cells appeared intact.

Two separate sections of skin were present on each of the three submitted slides. The epidermis was slightly acanthotic, and the subjacent dermis diffusely fibrotic. At the deep surgical excision margin basophilic alteration of dermal collagen and extravasated erythrocytes were present, along with mixed inflammatory cell infiltrates. The morphological appearance of the latter area was similar to the fibrinopurulent changes noted at the edges of the specimens above. Mixed inflammatory cell infiltrates were present throughout the fibrotic reticular dermis as was extravasation of erythrocytes. In addition, brightly eosinophilic fibrinoid material was present within the lumens of some of the small- and medium-sized blood vessels, but endothelial cell necrosis was not apparent. At the edge of the sections, reactive proliferating epidermis was present. Near this latter area, a medium-sized blood vessel with a recanalized lumen was present.

\section{Case 2}

Case 2 was a 64-year-old black female, whose presentation was in many ways classical for warfarin necrosis. Grossly obese, with a weight in excess of $155.5 \mathrm{~kg}$, she had suffered from hypertension for many years. A cerebrovascular accident nine years before had led to a degree of hemiparesis, and she first presented with another mild stroke. Another stroke rapidly followed, prompting her admission. Attempts to investigate the repeated neurological events led to administration of intravenous contrast material that set off an adverse reaction, resulting in acute renal failure. While in hospital for this problem, she developed a deep vein thrombosis and was anticoagulated with heparin, converting to warfarin after a few days. Approximately seven days after starting warfarin, she developed erythematous lesions over the abdominal pannus, the right hip and upper right thigh. These lesions rapidly evolved into frankly ischemic and then necrotic areas. The diagnosis of warfarin necrosis was entertained, and the warfarin was discontinued 10 days after administration. Blood tests performed at this time revealed a protein $\mathrm{C}$ deficiency, the level being $54 \%$ of normal, as well as an antithrombin III level of $67 \%$ of normal, thus confirming the diagnosis. The areas of necrosis were treated by excision and serial dressings, and the wounds were starting to granulate when the patient died of multiple medical problems two weeks later. No organisms were cultured from the wounds, and tissue taken for pathology at the time of excision was lost in transit, so histology was not available.

\section{PATHOPHYSIOLOGY}

Possibly because of its sporadic occurrence, the precise etiology of warfarinrelated necrosis is still enigmatic. Thrombosis, hypersensitivity, hemorrhage, factor VII 
deficiency and direct toxic effects have all been proposed as forming the basis of the observed pathology (8). All these explanations have been discussed extensively by Viegas (8), and each has been shown to be wanting.

Since the early 1970 s there have been suggestions of a link between warfarininduced reductions of the vitamin $\mathrm{K}$ dependent proteins and observations of warfarinrelated skin necrosis. In 1983, Broekmans et al (12) reported two patients with warfarininduced skin necrosis who were also deficient in protein C. Since then there have been reports of an association between congenital heterozygous protein $\mathrm{C}$ deficiency and skin necrosis, as well as skin necrosis in the face of normal levels of proteins $\mathrm{C}$ and $\mathrm{S}$ and antithrombin III $(3,13)$. More recently, there has been some interest in the possibility that a transient depression in the levels of protein $\mathrm{C}$ and/or protein $\mathrm{S}$ may be implicated. The theory is that a sudden fall in the level of one or more of the proteins regulating thrombosis, such as proteins $\mathrm{C}, \mathrm{S}$ or antithrombin III, will precipitate a hypercoagulable state, which in the face of a localized insult may precipate skin necrosis. Protein $\mathrm{C}$ is a vitamin $\mathrm{K}$ dependent glycoprotein that inhibits the activation of coagulation factors $\mathrm{Va}$ and VIIIa. Protein S is a cofactor that regulates the activity of protein C. It is well recognized that homozygous deficiencies of protein $\mathrm{C}$ are associated with skin necrosis (3), and a transient decrease in serum levels is a known risk factor because blood is thus rendered hypercoagulable (4). It has also been shown that during the first five days of warfarin therapy, there is a critical decrease in protein $\mathrm{C}$ synthesis, which might account for local thrombosis of venules (10). Counting against this broad etiological role for the antithrombotic proteins are two observations. First, that warfarin-related necrosis can occur without evidence of depression of protein $\mathrm{C}$ or S levels, as was seen in the index case reported here and as has been previously reported $(4,13)$. Second, while in the majority of cases necrosis follows within the first few days of starting warfarin therapy, there have been numerous reports of its occurrence weeks to months after initiating oral anticoagulation (11). Indeed, Nalbandian et al (7) and Jillson (14) have suggested that the complication of soft tissue necrosis may be more prevalent in patients who have had multiple courses of warfarin therapy.

Direct warfarin toxicity has also been proposed as a mechanism for the observed necrosis. At therapeutic doses, however, there is no evidence from either animal models or clinical observations to suggest direct toxic effects. Nonetheless, McCarter et al (15) were able to show, using dogs, that in supratherapeutic doses, warfarin led to hemorrhages, toxic lesions of small vessels, acute glomerular swelling and toxic lymphoid reactions. Based on their reading of the literature, and in particular the work of Humble (16), Neumayr and Schmid (17), and McCarter et al (15), Nalbandian et al (7) proposed that warfarin congeners were capable of exerting a toxic effect on vascular endothelium. Their synthesis was that an initial toxic insult was localized to the dermovascular loop, precisely at the junction of the capillary and arteriole. Such a location would account for the clinical observation that there is usually an evanescent flush (correlating with capillary dilation in the loop), followed by petechiae and ecchymoses, before going on to frank necrosis, secondary to sludging of blood, and leading to thrombosis in the venules distal to the dermovascular loop and the larger dermal and subcutaneous veins. The petechiae would correlate with capillary wall ruptures at the junction of the precapillary arteriole and capillary, and the ecchymoses with the coalescence of petechiae, amplified by the background of warfarin-induced 
depression of prothrombin levels. A more modern synthesis might substitute a transient hypercoagulability, such as secondary to decreases in protein $\mathrm{C}$ (heterozygous inheritance, large loading doses of warfarin) (3), decreases in protein S (pregnancy, nephrotic syndrome, systemic lupus erythematosis, liver disease, oral contraceptive use, disseminated intravascular coagulation) (4), or antithrombin III deficiency, as the primary insult. This would lead to an imbalance between the vitamin K dependent pro- and anticoagulant proteins (18), such that any local insult, including a putative toxicity, causing venular sludging might precipitate the clinical sequence of petechiae, ecchymosis and necrosis.

\section{DISCUSSION}

The above two case reports present several points of interest. Case 1 appears to be the first case in the world literature of a probable warfarin-related necrosis of soft tissues involving the upper extremity below the elbow. The evidence for warfarin being the key etiological agent includes the clinical presentation, with an exquisitely painful lesion, spontaneous in onset and progressing rapidly to frank, hemorrhagic necrosis of the involved skin; the natural history and evolution of the lesion on the hand, which, with largely conservative therapy produced an excellent result, are also suggestive. That this was not an infective phenomenon is supported by the failure of repeated attempts to culture an infective microorganism, and the complete absence of purulence. The histology, although equivocal, is not inconsistent with the diagnosis, and the reduced protein $\mathrm{S}$ level is virtually pathognomonic.

By contrast, the second case is an example of what may be termed the 'classic presentation' of warfarin-related necrosis. Here, the patient was female, middle-aged and obese. The onset of symptoms was, again typically, within a few days of commencing warfarin therapy. The sites of involvement, namely the abdomen, hip and thigh, were all areas with a significant amount of subcutaneous fat, and are the sites most frequently reported to be involved with this disease process. Progression of the lesions was halted by cessation of oral anticoagulants, as was the case in the index patient. The finding of significant reductions in proteins $\mathrm{C}$ and antithrombin III are again pathognomonic.

Treatment strategies, in both cases, were similar. Frankly necrotic tissue was debrided, and the wounds were dressed twice daily with saline-moistened gauze and a dry bandage. Both wounds showed signs of early healing, but this initial recovery was obviously cut short by the patient's death in case 2 . The first patient was referred to the hand rehabilitation service for active range of movement exercises, and a complete recovery of function was achieved. The soft tissue defect on the dorsal hand healed completely within six weeks.

This report contrasts the classical presentation of a poorly understood but common clinical phenomenon, with a rather more unusual presentation of the same pathology in the upper extremity. The index case manifestation, with involvement of the dorsal surface of the hand, appears to be extremely rare. Nevertheless, this constitutes yet another pathological entity to be borne in mind when confronted with a patient who presents with a suggestive area of rapidly evolving skin necrosis. 


\section{REFERENCES}

1. McKnight JT, Maxwell AJ, Anderson RL. Warfarin necrosis. Arch Fam Med 1992;1:105-8.

2. Link KP. Discovery of dicumarols and its sequels. Circulation 1959;19:97-101.

3. Eby CS. Warfarin-induced skin necrosis. Hematol Oncol Clin North Am 1993;7:1291300 .

4. Berkompas DC. Coumadin skin necrosis in a patient with a free protein S deficiency. Indiana Med 1991;November:788-91.

5. Lopez Valle C, Hebert G. Warfarin-induced complete bilateral breast necrosis. Br J

Plast Surg 1992;45:606-9.

6. Soisson AP, Vu KK. An unusual cutaneous reaction to anticoagulant therapy. Mil Med 1994;159:252-3.

7. Nalbandian RM, Mader IJ, Barrett JL, Pearce JF, Rupp EC. Petechiae ecchymoses, and necrosis of skin induced by coumarin congeners. JAMA 1965;192:107-12.

8. Viegas GV. Coumadin skin necrosis: Pedal manifestations. J Am Podiatr Med Assoc 1992;82:463-70.

9. LaPrade RF, Fowler B, Ryan TG. Skin necrosis with minidose warfarin used for prophylaxis against thromboembolic disease after hip surgery. Orthopedics 1993;16:7034.

10. Zauber NP, Stark MW. Successful warfarin anticoagulation despite protein C deficiency and a history of warfarin necrosis. Ann Intern Med 1986;104:659-64.

11. Cole MS, Minifee PK, Wolma FJ. Coumarin necrosis - A review of the literature. Surgery 1988;103:271-8.

12. Broekmans AW, Bertina RM, Loeliger EA. Protein C and the development of skin necrosis during anticoagulant therapy. Thromb Haemost 1983;49:251-5.

13. McGehee WG, Klotz T, Epstein DJ. Coumarin necrosis associated with hereditary protein C deficiency. Ann Intern Med 1984;101:59-64.

14. Jillson OF. Coumarin-induced necrosis. Arch Dermatol 1980;116:44-6.

15. McCarter JC, Bingham JB, Meyer OO. Studies on the hemorrhagic agent

3,3:methylene-bis-(4-hydroxycoumarin): The pathologic findings after administration of dicoumarol. Am J Pathol 1944;20:651-6.

16. Humble JG. Mechanism of petechial hemorrhage formation. Blood 1949;4:69-75.

17. Neumayr A, Schmid J. Kapillapermeabilitat unt antithrombon. Schweiz Med Wochenschr 1948;25:616-8.

18. McKnight JT, Maxwell AJ, Anderson RL. Warfarin necrosis. Arch Fam Med 1992;1:105-8. 